\title{
Human Cells, Tissues, and Cellular and Tissue-Based Products Microorganism Testing Only
}

National Cancer Institute

\section{Source}

National Cancer Institute. Human Cells, Tissues, and Cellular and Tissue-Based Products Microorganism Testing Only. NCI Thesaurus. Code C133291.

Testing a representative sample of Human Cells, $\mathrm{T}$ issues, and Cellular and $\mathrm{T}$ issue-Based Products (HCT/Ps) to detect microorganisms is the only function performed by the establishment. 